\title{
Hybrid carbon fibre/nylon 12 single polymer composites
}

\author{
P.J.Hine ${ }^{1 *}$, M.Bonner ${ }^{1}$, I.M.Ward ${ }^{1}$, Y.Swolfs ${ }^{2}$, I. Verpoest ${ }^{2}$, A. Mierzwa ${ }^{3}$ \\ ${ }^{1}$ Soft Matter Group, University of Leeds, Leeds, LS2 9JT \\ ${ }^{2}$ Department of Materials Engineering KU Leuven Kasteelpark Arenberg 44, B-3001 Leuven \\ (Belgium) \\ ${ }^{3}$ Technische Universität München, Boltzmannstraße 1585748 Garching bei München \\ * Corresponding author (p.j.hine@leeds.ac.uk)
}

Keywords: A. Hybrid; A. Polymer-matrix composites (PMCs); B. Mechanical properties; D. Mechanical testing

\section{Abstract}

Single polymer composites (SPC) are finding increasing use due to their novel combination of lightweight and high toughness. This paper describes an investigation into the production and properties of hybrid single polymer composites (SPC) made from co-mingled tows of carbon fibres and nylon 12 (PA12) oriented multifilaments, using the Leeds hot compaction process. The aim of the study was to investigate ways to increase the stiffness of the SPC (by the addition of carbon fibres) without significantly compromising ductility and impact performance which a feature of SPCs.

Experiments showed that the optimum processing temperature required for the production of the hybrid composites using the hot compaction technique depended on both the arrangement of the hybrid tows and the fraction of carbon fibres. For $22 \%$ volume fraction of carbon fibres, a well consolidated sample could be made at a temperature of $176^{\circ} \mathrm{C}, 2^{\circ} \mathrm{C}$ below the temperature at which major crystalline melting of the oriented PA12 fibres, and loss of molecular orientation, occurs. For braided cloth made from the same co-mingled tows, a higher temperature of $178^{\circ} \mathrm{C}$ was required to give a well consolidated sample. A combination of wide angle x-ray (WAXS) and differential scanning calorimetry (DSC) measurements showed that this temperature was too close to the melting point of the PA12 multifilaments. For co-mingled tows containing 13\% carbon fibres it was found that a well consolidated sample could be made from braided cloth using a lower temperature of $175^{\circ} \mathrm{C}$. At this temperature, sufficient melted and recrystallised matrix material was produced to consolidate the structure and produce a homogeneous composite. This temperature was $3^{\circ} \mathrm{C}$ below the temperature at which substantial crystalline melting occurred, giving a usable temperature processing window. In tension the hybrid samples were found to fail in a brittle manner, with the whole sample breaking on failure of the carbon fibres. The hybrid samples were found to show ductile behaviour in bending as long as a substantial proportion of the molecular orientation of the PA12 fibres was retained.

\section{Introduction}

Traditional carbon fibre composites deliver exceptional stiffness and strength but can often have a limited extensibility and poor damage tolerance especially at low operating temperatures. On the other hand, the development of single polymer composites over the last 20 years has seen the emergence of a new material that is lightweight and has exceptional toughness even at low temperatures, but often with limited stiffness. This work has investigated methods to combine the best attributes of these two material types by creating a self-reinforced, single polymer/carbon fibre hybrid. The aim is to produce a single polymer composite material that has enhanced stiffness without sacrificing the excellent toughness and ductility usually shown by these materials.

The concept of combining a high stiffness, but brittle, fibre with a ductile polymeric fibre with a much larger strain to failure has been widely researched. Pegoretti [1] described the extensive fibre 
combinations that had been reported in the literature at that time (2004), including carbon/glass, carbon/Kevlar, carbon/ultra-high-modulus-polyethylene (UHMPE), aramid/UHMPE and UHMPE/glass. In all of these 'hybrid' composites the main purpose is to add a proportion of ductile fibres to a carbon fibre composite to increase the failure strain and energy absorbing capabilities of the usually brittle material. In particular, Pegoretti found a significant increase in the ductility index, which is a ratio of the propagation energy to the initiation energy, for hybrid intraply composites of glass and PVA fibres.

This area of research continues to be of interest with recent papers by Saw et al [2] who investigated the possibilities of hybridising two types of jute and coir fibres while Wan et al [3] investigated three dimensional braiding of carbon and Kevlar fibres. Czél and Wisnom [4] more recently have looked at improving brittle behavior by employing thin laminate layers.

The work presented in this paper differs from these previous studies in two crucial aspects. First, although the hybrid composite materials reported here have the same three components as those described above, that is a brittle fibre, a ductile fibre and a matrix, the method of generating the matrix phase is completely different to most of the previously published work as it is produced from the ductile fibres using a process developed at the University of Leeds termed hot compaction. These materials are often termed single polymer, or self reinforced polymer composites (SRPC). Second, the goal of the research is different to the majority of the published studies where the aim is to increase the energy absorbing capacity of a carbon fibre reinforced polymer matrix composite by adding in a fraction of ductile fibres. In the current work the goal was opposite to this, that is to add a small fraction of carbon fibres to an already ductile composite material to increase stiffness without, if possible, compromising ductility.

While there are a number of published methods for producing single polymer composites (for example solvent impregnation [5], film stacking [6,7], powder impregnation [8, 9], fibres with differing melting points [10] and bi-component tapes[11, 12]), the one used for this study was developed and patented at the University of Leeds [13-15] and is termed hot compaction. Figure 1 shows a schematic of the process for oriented polymer fibres. The underlying principle is to take assemblies of oriented homopolymer fibres or tapes, and expose them to a critical temperature, while held under pressure, such that a thin skin on the surface of each oriented element is 'selectively melted'. On subsequent fast cooling, the melted material recrystallises to form the matrix phase of a single polymer composite, with the remaining fraction of the original oriented phase acting as the reinforcement. The virtues of this technique are that the matrix phase is produced around each fibre, negating the need for infiltration, and that molecular continuity is achieved between the two components of the final composite. Research has shown this to work with a wide range of oriented thermoplastic fibres and tapes including polyethylene [16], polypropylene [17], polyester [18] and nylon 6.6 [19]. 

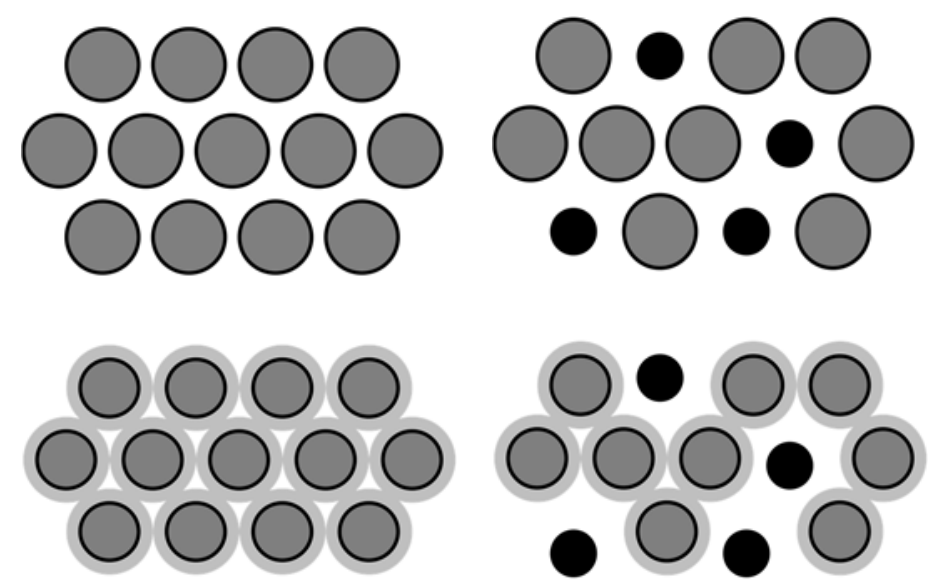

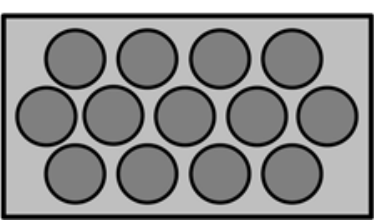

(a)

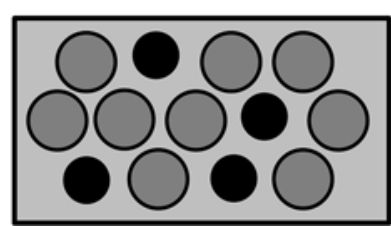

(b)

Figure 1: A schematic of the hot compaction process for (a) oriented PA12 polymer fibres and (b) for co-mingled carbon (O) and oriented PA12 fibres $\left({ }^{\circ}\right)$

The production of hybridised single polymer composites is very much a new research area. Of the few studies carried out, Taketa and Fabich [20,21], have looked at combining discrete layers of a carbon fibre (prepreg) composite and a single polymer (SPC) sheet, termed inter-layer hybridisaton. Taketa found that the failure strain of the hybrid laminate was improved over the pure carbon fibre laminate and this was associated with a compressive pre-strain associated with the shrinkage of the SRP fraction during consolidation and cooling, while Fabich found some beneficial effects on the impact performance. In his review of hybrid composites, Kretsis [22] discusses the most important factors that he considers can provide a positive hybrid effect, defined as a measured property that lies above the prediction of the rule of mixtures. These included thickness effects, the comparative properties of the constituents, the level of adhesion between the constituents and the dispersion of the constituents. Kretsis cites the work of Manders and Bader [23] for their investigation of the effects of dispersion, defined as the reciprocal of the smallest repeat unit of the composite. They found that where hybrids had been fabricated with a constant glass:carbon ratio (and therefore a similar thermal effect), but with different degrees of dispersion, the hybrid effect was greater in the more highly dispersed materials. Taking inspiration from this conclusion, we have built upon the initial studies of Taketa and Fabich on interlayer hybridization to systems where the level of dispersion is increased. In a recent paper [24], we described the beneficial effect of intra-layer hybridization, where each layer was comprised of cowoven tapes of oriented polypropylene and carbon fibre/polypropylene tapes.

In this current reported study we have taken this one step further, and again increased the dispersion by using intra-yarn hybridisation. Here each individual yarn is a mixture of oriented polymer fibres (in this case oriented Nylon 12) and carbon fibres. For this work, co-mingled tows of oriented PA12 fibres and carbon fibres were supplied in two carbon fibre volume fractions: $22 \%$ and $13 \%$. The tows were either processed using the hot compaction technique into UD composites, or woven or braided into a cloth using standard textile techniques and then processed to form a balanced consolidated hybrid composite. 
The key challenge in the hot compaction process for a mixture of carbon and polymer fibres is that there are now less polymer fibres to produce the matrix phase, as shown schematically in Figure $1 b$. Experiments have therefore been carried out to establish whether a homogenous composite can be produced using such a co-mingled yarn, and whether this depends on either the fraction of carbon fibres, the arrangement of the fibres (UD, braided etc) or both. Samples from a variety of fibre arrangements were produced for a range of compaction temperatures around the melting temperature of the PA12 fibres. Tensile and bending tests were then carried out to determine the mechanical properties of these various samples to assess the optimum configuration and processing conditions.

\section{Experimental}

\subsection{Materials}

The co-mingled yarns (carbon fibres and oriented PA12 filaments) for this study were produced by Schappe Techniques, France using their patented stretch breaking technology. In the stretch breaking process (for other examples see references [25] and [26]) continuous yarns are passed over rollers in order to create conformable yarns comprised of discontinuous fibres with a very long aspect ratio. For this project the yarns were supplied in two combinations, with nominally $25 \%$ volume fraction of carbon fibres and with $13 \%$ volume fraction of carbon fibres. Microscopy of the combined tows showed that the mingling of the two components was excellent. The carbon fibres used had a modulus of $240 \mathrm{GPa}$ and a strength of $4000 \mathrm{MPa}$

\subsection{Measurement of the carbon fibre fraction}

The fraction of carbon fibres in the two co-mingled tows was measured using the burn off test (ASTM D2184). Samples were heated in a porcelain crucible until the PA12 matrix ignited. The samples were then placed into a furnace set at $450^{\circ} \mathrm{C}$ and left for 4 hours to remove the carbonaceous residue. A measurement of the weight before and after the burn off allowed the weight fraction to be calculated. This fraction is converted into the carbon fibre volume fraction by assuming a density of respectively $1015 \mathrm{~kg} / \mathrm{m}^{3}$ and $1800 \mathrm{~kg} / \mathrm{m}^{3}$ for PA12 and CF. Measured values were a volume fraction of $22 \pm 1 \%$ and $13 \pm 1 \%$ for the two tows supplied by Schappe Techniques.

\subsection{Production of composite samples}

\subsubsection{Hot compaction trials}

Composite samples were produced using the Leeds hot compaction process [14]. The aim of this procedure is to establish a critical temperature at which a fraction of the oriented PA12 fibres are selectively melted (normally around $22 \%$ ), which then forms the matrix of the resulting single polymer composite. In this study, samples were made from a range of fibre arrangements to assess how this would affect the critical temperature and resulting mechanical properties.

A typical process is as follows. The oriented assembly is placed between aluminium sheets (thickness $0.1 \mathrm{~mm}$ ), two layers of silicon rubber to even out the pressure distribution, and then outer sheets of $2 \mathrm{~mm}$ thick brass sheets. A thermocouple is placed in the centre of the assembly, and this is used for monitoring the temperature throughout the process. The assembly is then placed into a compression press set at the required temperature. A pressure of $5 \mathrm{MPa}$ is immediately applied and temperature monitoring is started. Once the temperature reaches the required temperature, it is left for 2 minutes. The whole press is then rapidly cooled to $50^{\circ} \mathrm{C}$ (using circulated water cooling) at which point the sample is removed from the press. The whole process takes around 7 minutes. A typical processing schedule is shown in Figure 2. The dotted lines show the time at which the temperature reached the target value of $175^{\circ} \mathrm{C}$ and the subsequent start of the fast cooling regime, 120 seconds ( 2 minutes) later. 


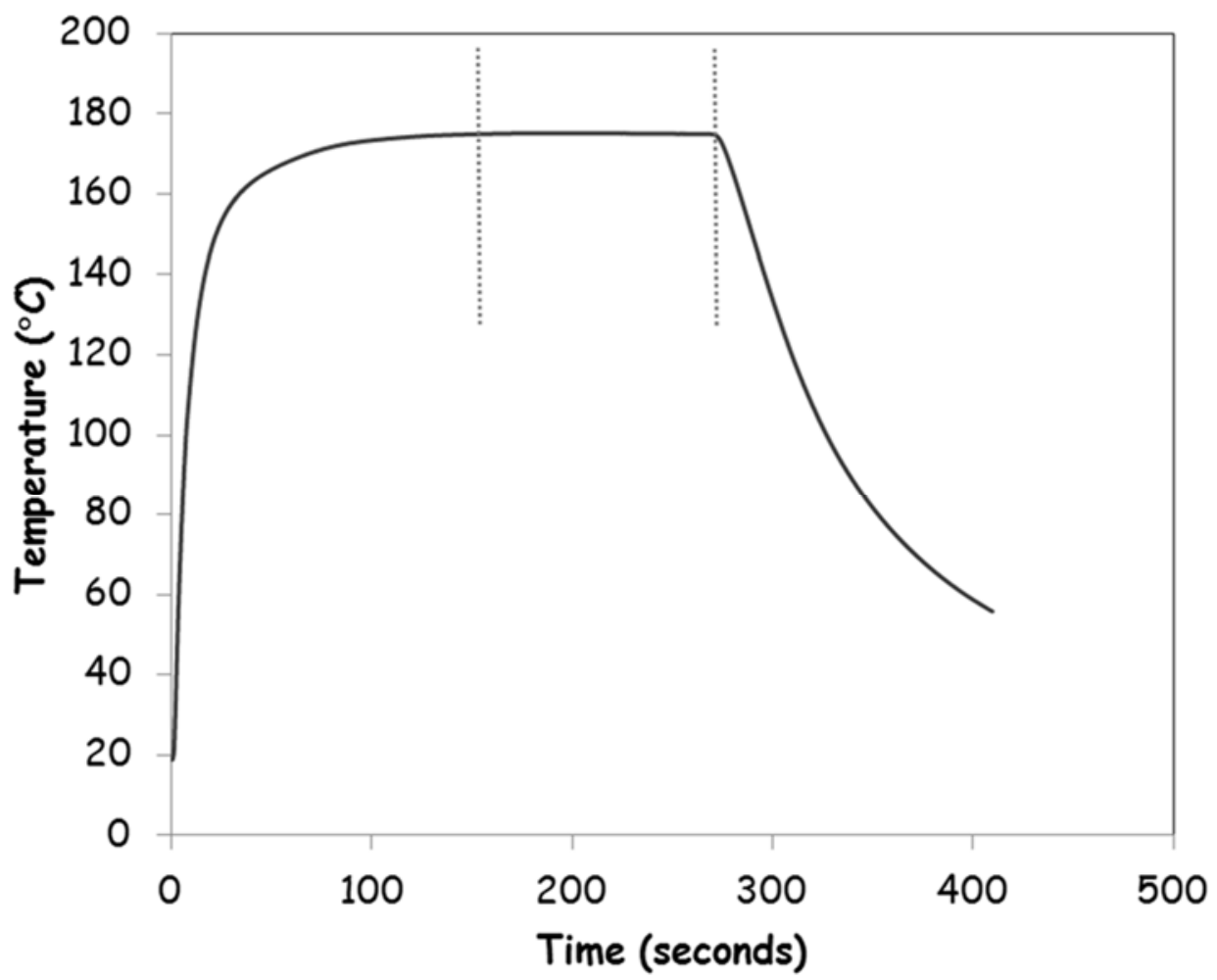

Figure 2: A typical process schedule for the production of a hybrid T700/SRPA12 sample. The dotted lines indicate the dwell time at the hot compaction temperature, in this case $175^{\circ} \mathrm{C}$.

\subsubsection{Fibre arrangement}

Samples were made from two configurations, first a UD arrangement by winding the co-mingled tows around a metal frame, and second from braided cloth made from the co-mingled fibre tows. The Herzog braiding machine at Technical University Munich (RF-128-100) uses a 128 bobbin set-up which can produce a tubular cloth with braiding angles between 30 and $60^{\circ}$. The $22 \%$ carbon fibre tows were $2 \mathrm{~mm}$ in diameter and could be successfully braided at an angle of $\pm 45^{\circ}$. Various tubular diameters were braided, the most successful (in terms of good coverage of the mandrel) was $60 \mathrm{~mm}$. Once braided, the tubular cloth was cut to provide layers of cloth for hot compaction trials. The style of braiding was biaxial. The $13 \%$ carbon fibre tow was of a smaller diameter $(\sim 1 \mathrm{~mm})$ and so the maximum diameter that could be braided, without gaps, was slightly lower at $50 \mathrm{~mm}$. Figure $3 \mathrm{a}$ shows a picture of the braided cloth from the $22 \%$ carbon fibre tows and Figure $3 \mathrm{~b}$ from the $13 \%$ carbon fibre tows. In both cases the bottom axis of the picture is $100 \mathrm{~mm}$ long.
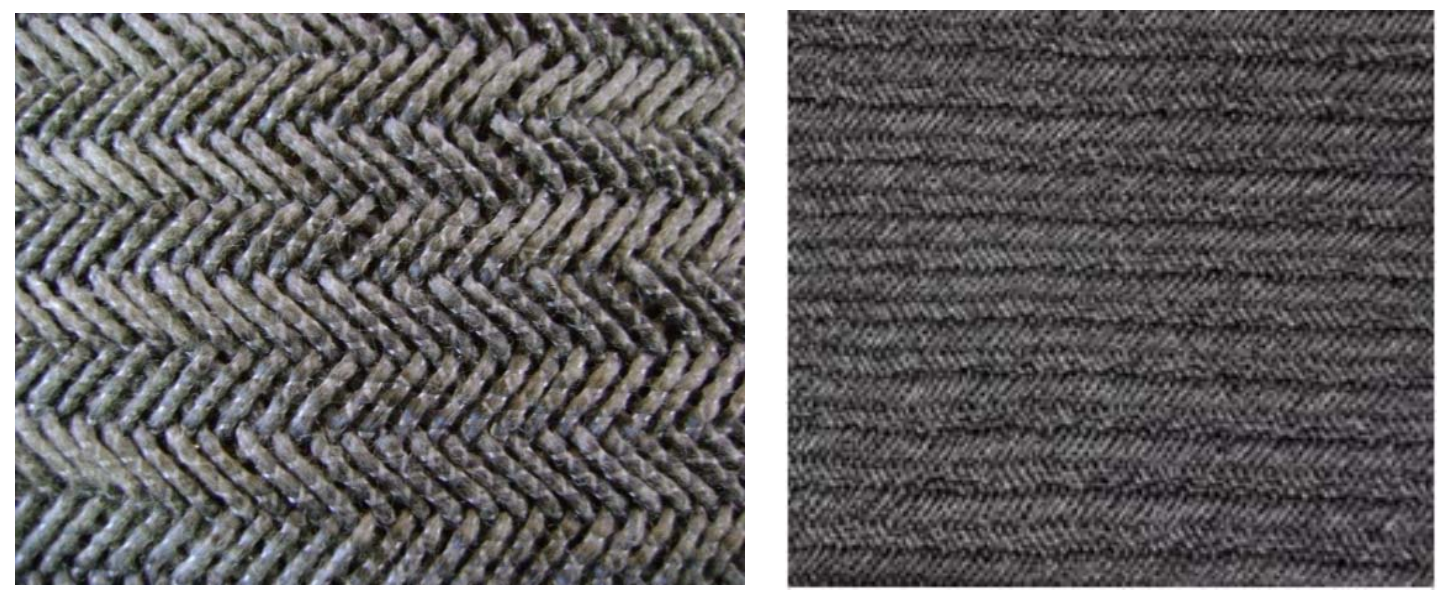

Figure 3: Examples of braided cloth. Left hand side from $22 \%$ carbon fibre co-mingled tows, right hand side from $13 \%$ carbon fibre co-mingled tows. The bottom axis of both images is equal to $100 \mathrm{~mm}$. 


\subsection{Characterisation and testing}

\subsubsection{Mechanical testing}

Both tensile and bending tests were carried out on the hybrid composite samples. These were carried out in accordance with ASTM D3039 (tensile) and ASTM D6272 (bending), at a temperature of $20^{\circ} \mathrm{C}$ and $50 \%$ RH. Samples were left to equilibrate at these conditions for 5 days before testing. While the properties of Nylons are well known to be affected by moisture uptake, Nylon 12 is the least affected and normally has an equilibrium water uptake of between 0.5 and $1 \%$.

The tensile test samples were $10 \mathrm{~mm}$ wide and $150 \mathrm{~mm}$ long. The gauge length was set to $65 \mathrm{~mm}$ and the sample strain was measured in the centre $15 \mathrm{~mm}$ using a Messphysik video-extensometer. The testing speed was $5 \mathrm{~mm} / \mathrm{min}$, giving a nominal strain rate of $10^{-3} \mathrm{~s}^{-1}$.

The bending test samples were $10 \mathrm{~mm}$ wide and $70 \mathrm{~mm}$ long. Modulus measurements were made using a span/thickness ratio of 25:1 while stress-strain curves to break were made using a span/thickness ratio of 16:1 as recommended by the standard. The testing speed was chosen to be $5 \mathrm{~mm} / \mathrm{min}$, to give the same strain rate as for the tensile tests of $10^{-3} \mathrm{~s}^{-1}$.

\subsubsection{Wide angle $x$-ray scattering}

Wide angle $x$-ray scattering (WAXS) pictures and scans were taken from the various UD samples to follow the loss of molecular orientation over the critical hot compaction temperature range. A qualitative measurement of the orientation was first taken using a flat X-ray camera located $40 \mathrm{~mm}$ from the sample. The sample was exposed to copper $\mathrm{K}_{\alpha} \mathrm{X}$-rays for one hour and the subsequent negative was developed to show the x-ray scattering picture. More detailed quantitative scans were then carried out over regions of interest in $2 \theta$ space using a computer controlled Huber goniometer.

\subsubsection{Differential scanning calorimetry}

Differential scanning calorimetry was also carried out on the UD samples to give a second measurement of the change in crystalline structure of the PA12 fibres with various compaction temperatures. Experiments were carried out using a Perkin Elmer DCS-7 at a scanning rate of $10^{\circ} \mathrm{C} / \mathrm{min}$ in air.

\section{Results}

\subsection{UD samples - $22 \%$ carbon fibre tows - tension}

UD samples made from the $22 \%$ carbon fibre tows were made over a range of temperatures from $171^{\circ} \mathrm{C}$ to $179^{\circ} \mathrm{C}$ plus an additional sample made at $190^{\circ} \mathrm{C}$ to completely melt the PA12 fibres. Tensile tests were carried out on samples cut both parallel and perpendicular to the fibre direction for samples made over this temperature range and the results are shown in Figure 4. Figure 4a shows tensile stress strain curves for samples made over a range of compaction temperatures and tested in the fibre direction, while Figure $4 \mathrm{~b}$ shows the tensile strength of the same samples but tested transverse to the fibre direction.

In the fibre direction (Figure 4a) the results were seen to be almost independent of the hot compaction temperature, being dominated by the carbon fibres. Average results, for three tests on the sample made at $176^{\circ} \mathrm{C}$, were a tensile modulus of $62 \pm 3 \mathrm{GPa}$, a strength of $521 \pm 27 \mathrm{MPa}$ and a failure strain of 0.90 $\pm 0.07 \%$. The measured tensile modulus is just higher than the upper limit of 58GPa predicted from the measured fibre volume fraction $(22 \pm 1 \%$ ) and the properties of the two components (240GPa for the carbon fibres and 3.8GPa for a pure UD PA12 single polymer sheet). One possible reason is that 
there may be additional weight loss during the burn off and so the volume fraction may be slightly underestimated.

In the transverse direction (Figure 4b) the tensile strength was both significantly lower, as expected, but also highly dependent on the hot compaction temperature (i.e. the amount of selectively produced matrix phase), reaching a maximum value of $34.1 \pm 1.7 \mathrm{MPa}$ at $178^{\circ} \mathrm{C}$. A vital aspect of the hot compaction process is to be able to establish a temperature where good bonding can be achieved without substantial loss of molecular orientation of the oriented components. DSC and WAXS measurements were carried out on these compacted UD samples to investigate this aspect.

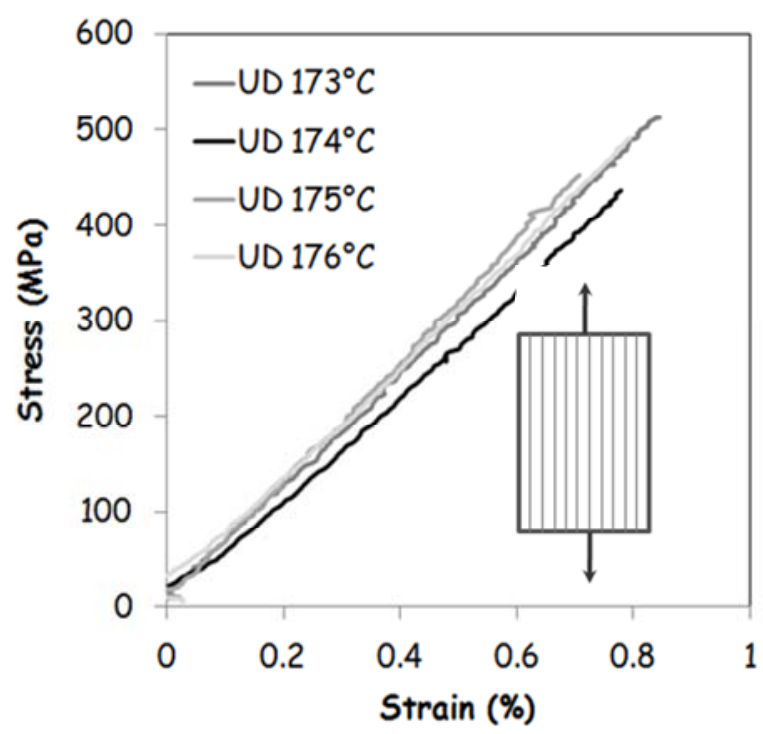

(a)

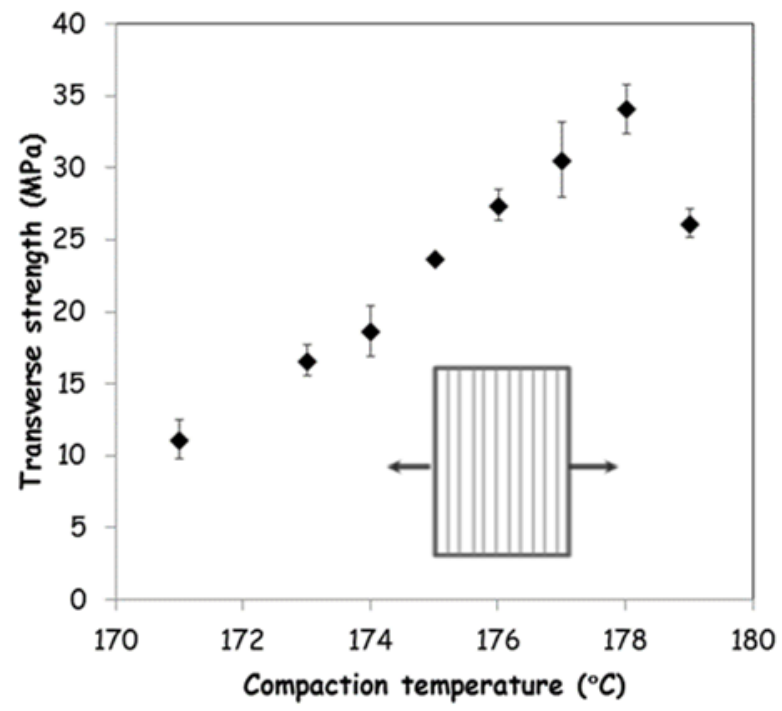

(b)

Figure 4: UD tensile results for $\mathbf{2 2 \%}$ volume fraction of carbon fibres for various hot compaction temperatures: a) tested in the fibre direction $b$ ) tested in the transverse direction

Figure 5 shows a set of DSC endotherms for samples compacted between 173 and $180^{\circ} \mathrm{C}$. For the sample made at $173^{\circ} \mathrm{C}$, there is only a single peak, which can be identified with the crystalline structure of the PA12 fibres before any substantial melting occurs. At $176^{\circ} \mathrm{C}$, the main peak can be seen to have moved up in temperature slightly, which is normally associated with increased homogeneity of the structure. There is also the suggestion of a second peak at a lower temperature. As the compaction temperature is increased, the lower peak (associated with the melted and recrystallised matrix phase) increases in size at the expense of the fibre peak, such that for the sample made at $180^{\circ} \mathrm{C}$ the majority of the structure is now the melted and recrystallised material and only a small percentage of the original fibre remains. 


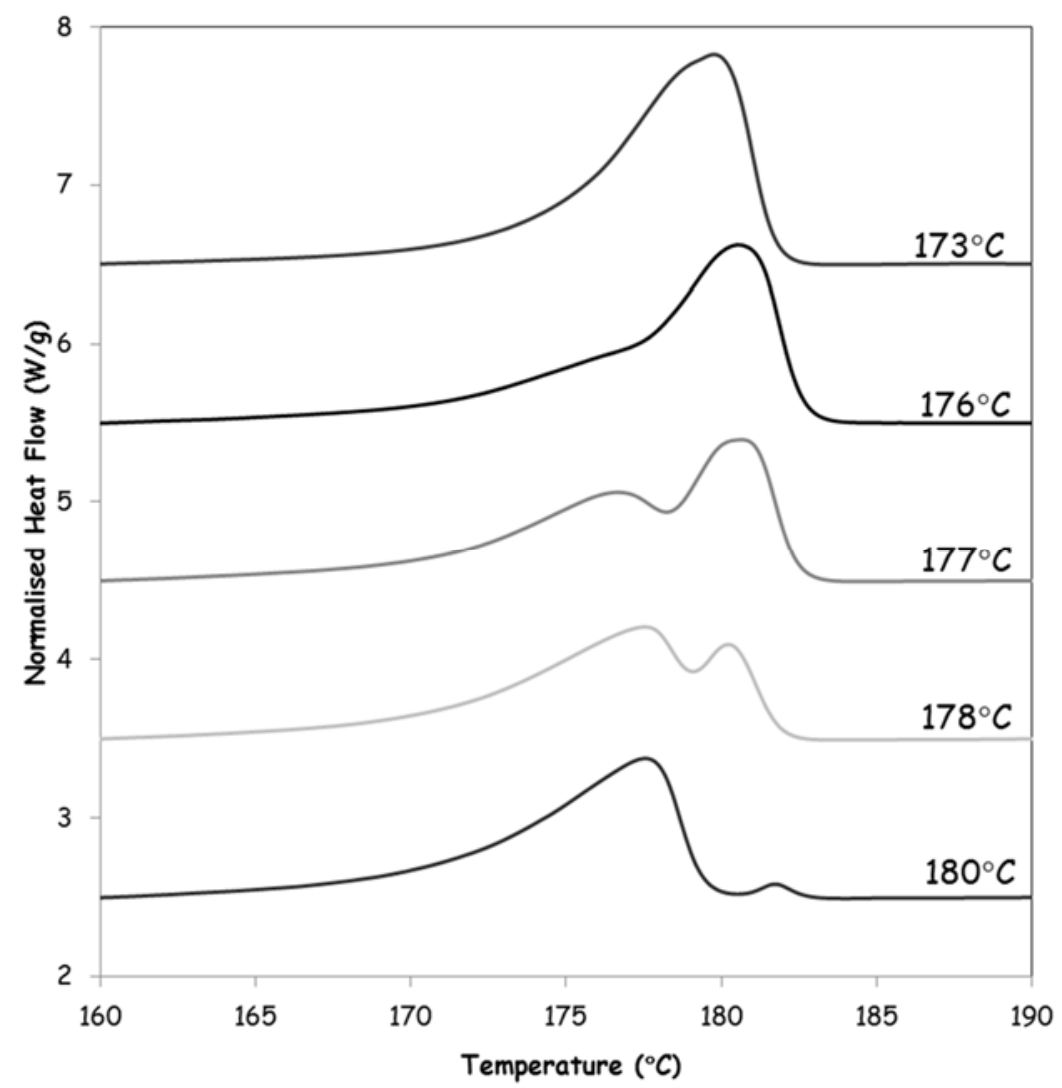

Figure 5: DSC melting endotherms for UD samples (22\% carbon fibre fraction) made over a range of hot compaction temperatures.

The DSC results can be used to determine an estimate of the fibre phase remaining at each compaction temperature. Normally, the peaks associated with the two phases (original fibres and recrystallised matrix) are well separated and the individual peaks areas can be determined to calculate directly the fractions of the two phases for a particular compaction temperature [27]. However, in this case where the peaks are much closer together, we have used a technique that we have successfully implemented before, which is to calculate the total area of the peaks for the various compaction temperatures. As the area of the peaks at the two extremes (no melting and complete melting) are different, with the $2^{\text {nd }}$ being lower, a measurement of the total peak area (between 160 and $190^{\circ} \mathrm{C}$ ) gives a measurement of the falling contribution from the upper peak, which is the remaining fibre fraction. Figure 6 shows the results of this determination, where the peak area has been normalised to the value at a temperature of $173^{\circ} \mathrm{C}$ where no selective melting has yet occurred. The results were found to show a very similar shape to that seen before in, for example, the hot compaction of melt spun PE fibres [27]. These results show that for a compaction temperature of $176^{\circ} \mathrm{C}$, there is around $70 \%$ of the original fibres remaining. This is close to the value that has been measured as optimum for previous studies on PE and PP. 


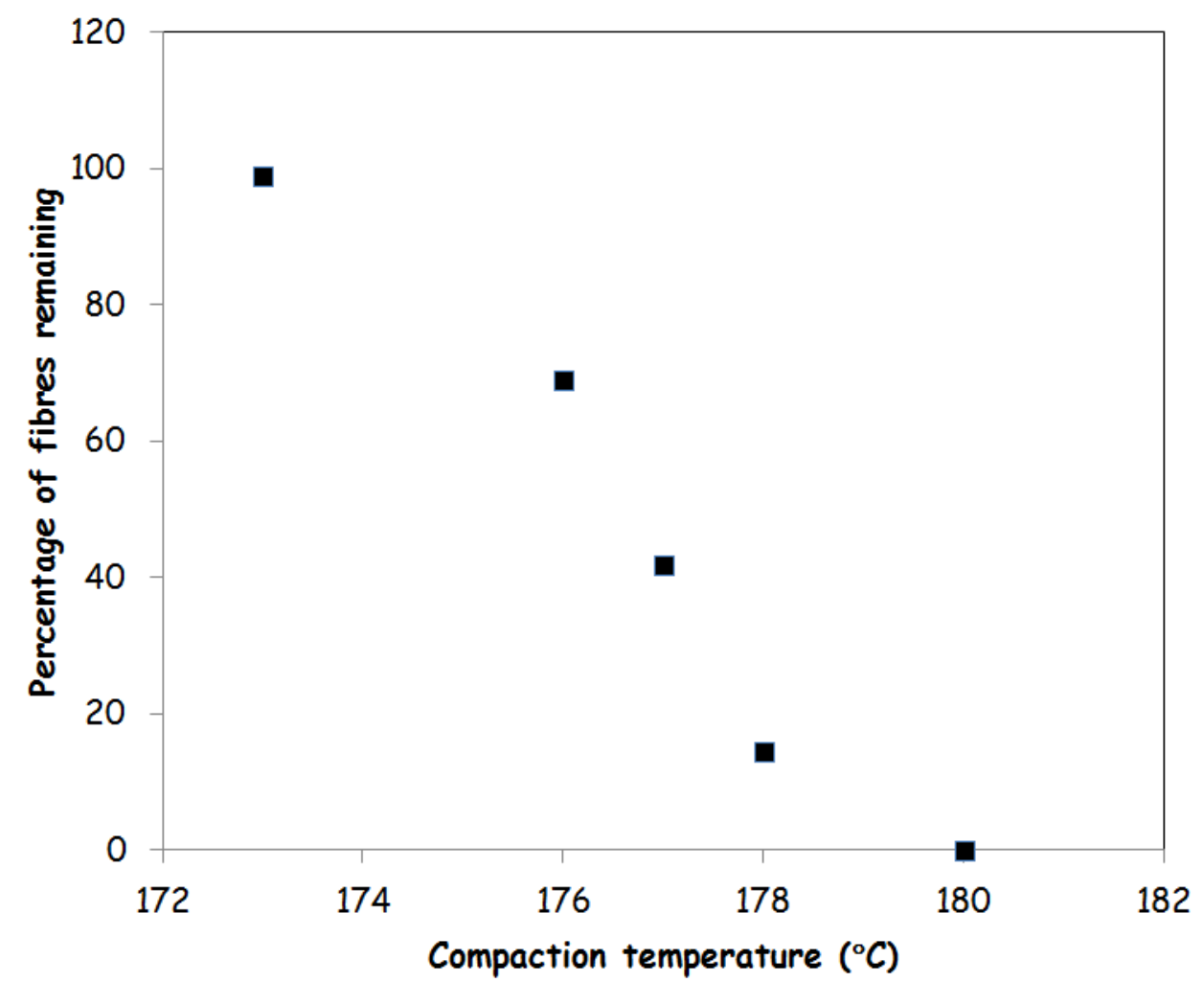

Figure 6: Percentage of the PA12 fibres remaining with hot compaction temperature.

WAXS photos are shown on Figure 7 for four different compaction temperatures, 171, 174, 176 and $179^{\circ} \mathrm{C}$ : in all the photos the fibre direction is vertical. The sample made a $171^{\circ} \mathrm{C}$ shows equatorial peaks (horizontal) at a value of $2 \theta$ of $21.4^{\circ}$ (associated with the oriented PA12 fibres) plus more diffuse equatorial peaks at a higher $2 \theta$ value of around $25.5^{\circ}$ associated with the carbon fibres. The PA12 equatorial peak is associated with the (001) crystalline reflection [28]. As the compaction temperature is increased it can be seen that the equatorial spots gradually transform into rings (at $179^{\circ} \mathrm{C}$ ) suggesting the oriented structure associated with the fibres has been lost as the fibres are melted and recrystallised in a random orientation. The photos also show meridional peaks (in the vertical direction) which are clearly visible at 171,174 and $176^{\circ} \mathrm{C}$, but are absent for the sample made at a compaction temperature of $179^{\circ} \mathrm{C}$. The white arrow on the photo from the sample at $174^{\circ} \mathrm{C}$ shows the position of the first meridional peak, and this was measured to occur at a value of $2 \theta$ of $5.8^{\circ}$ and can be associated with the (020) reflection [28]. The photos confirm major crystalline melting of the fibres has occurred by a compaction temperature of $179^{\circ} \mathrm{C}$, in good agreement with the DSC results. 

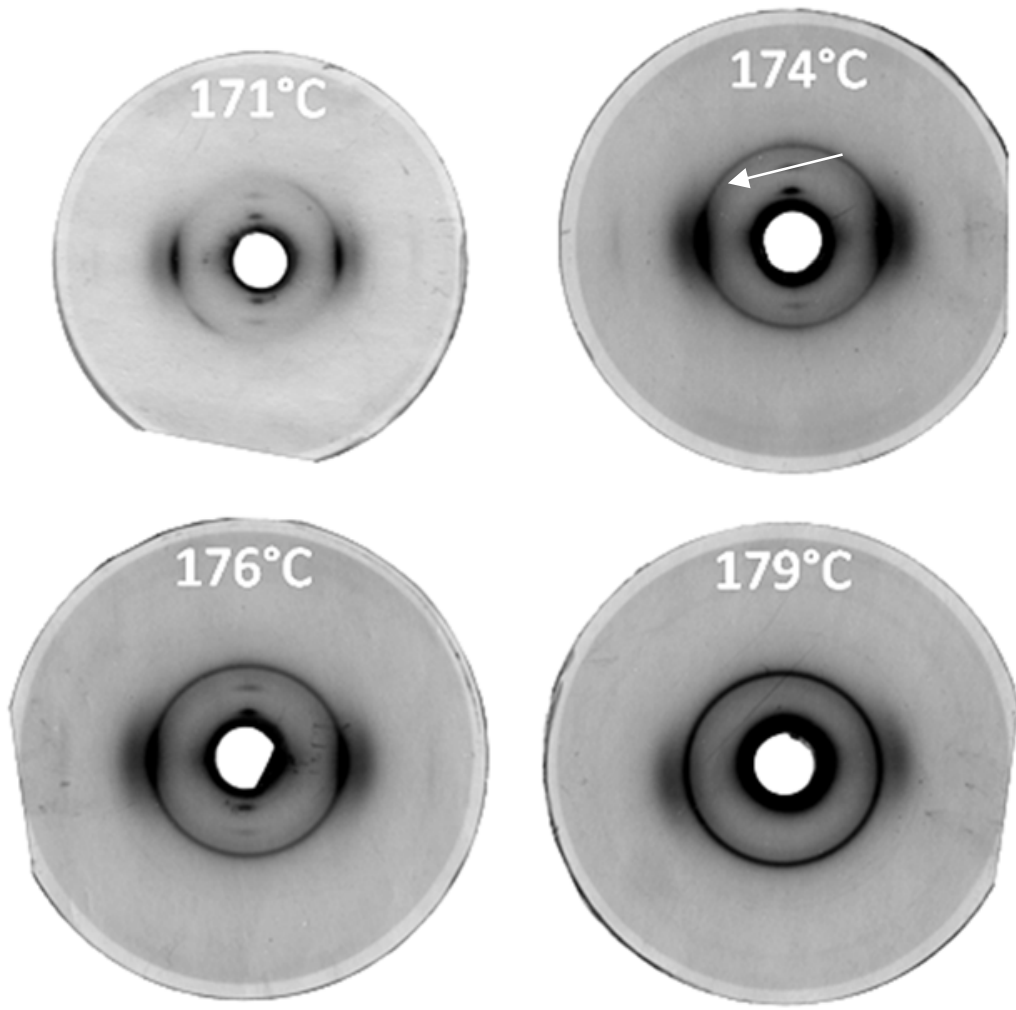

Figure 7: WAXS pictures from UD samples produced at $171,174,176$ and $179^{\circ} \mathrm{C}$. The sample direction is vertical for taking these photos. The white arrow on the $174^{\circ} \mathrm{C}$ photo shows the 020 meridional peak.

Quantitative circumferential scans were carried out using the x-ray diffractometer around the meridional position (alpha $=0^{\circ}$ ), for a value of $2 \theta$ of $5.8^{\circ}$. This is the first meridional peak, which is characteristic of the crystalline structure of the oriented PA12 fibres. Figure 8 shows the results of these scans for the various compacted UD samples. It is seen that as the compaction temperature is increased the strength of the (020) reflection reduces, disappearing completely between 178 and $180^{\circ} \mathrm{C}$ in line with the WAXS photos and the DSC measurements. Interestingly, the full width half height of the peaks is little changed between the original fibres $(14 \pm 1)^{\circ}$ and the compacted sample made at $178^{\circ} \mathrm{C}(15 \pm 1)^{\circ}$. This shows that both the winding technique produces excellent fibre alignment, but also that increasing the compaction temperature does not significantly reduce the preferred orientation of the PA12 fibres, but rather just selectively melts a fraction of the surface determined by temperature itself. 


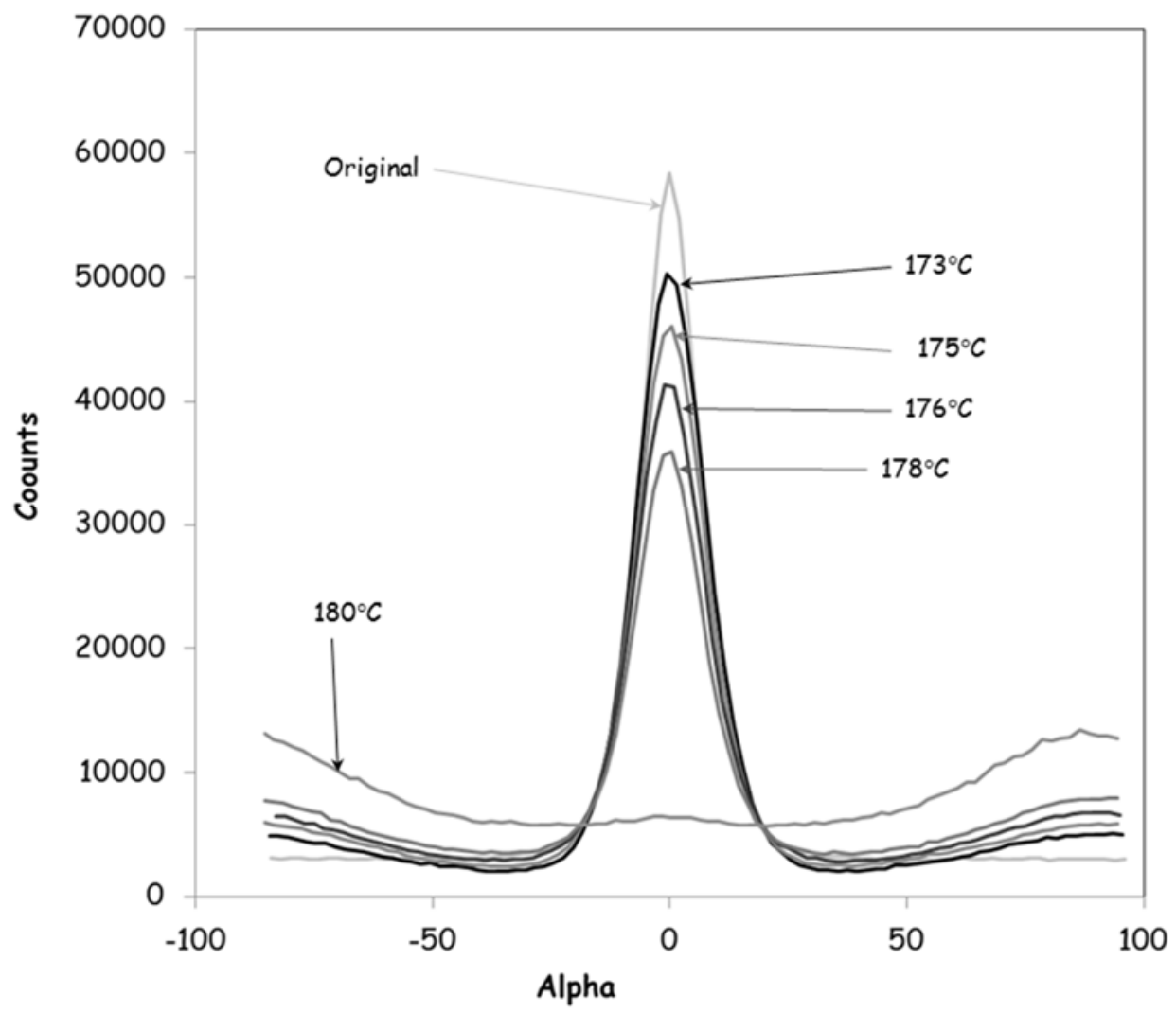

Figure 8: Circumferential diffractometer scans of compacted samples made over a range of temperatures: $2 \theta=5.8^{\circ}$ : alpha $=\mathbf{0}$ is vertical.

The combination of the DSC and WAXS results suggests an optimum and safe compaction temperature of $\sim 176^{\circ} \mathrm{C}$, which is $\sim 3^{\circ}$ below the point at which all the oriented structure is lost.

\subsection{UD samples - $22 \%$ carbon fibre tows - bending}

In the next set of experiments, bending tests were carried out on a range of samples in the fibre direction. As with the longitudinal tensile tests, the results for the bending modulus tested in the fibre direction were reasonably independent of the compaction temperature. The average value for the bending modulus and strength were lower than seen in tension, with values of $34 \pm 1 \mathrm{GPa}$ and $377 \pm$ $43 \mathrm{MPa}$ respectively. Polymer based composites can often show a lower modulus in bending compared to tension due to the much easier deformation mode of shear. However, there were two vital differences in failure mode compared to the tensile tests. First, as seen from a representative sample shown in Figure 9 and made at $173^{\circ} \mathrm{C}$, the samples all failed in a ductile manner in bending, compared to the brittle behaviour seen in tension. Catastrophic failure of the sample did not occur when the carbon fibres broke on the tension side of the sample. The compressive side of the sample continued to bear load to around $8 \%$ strain. 


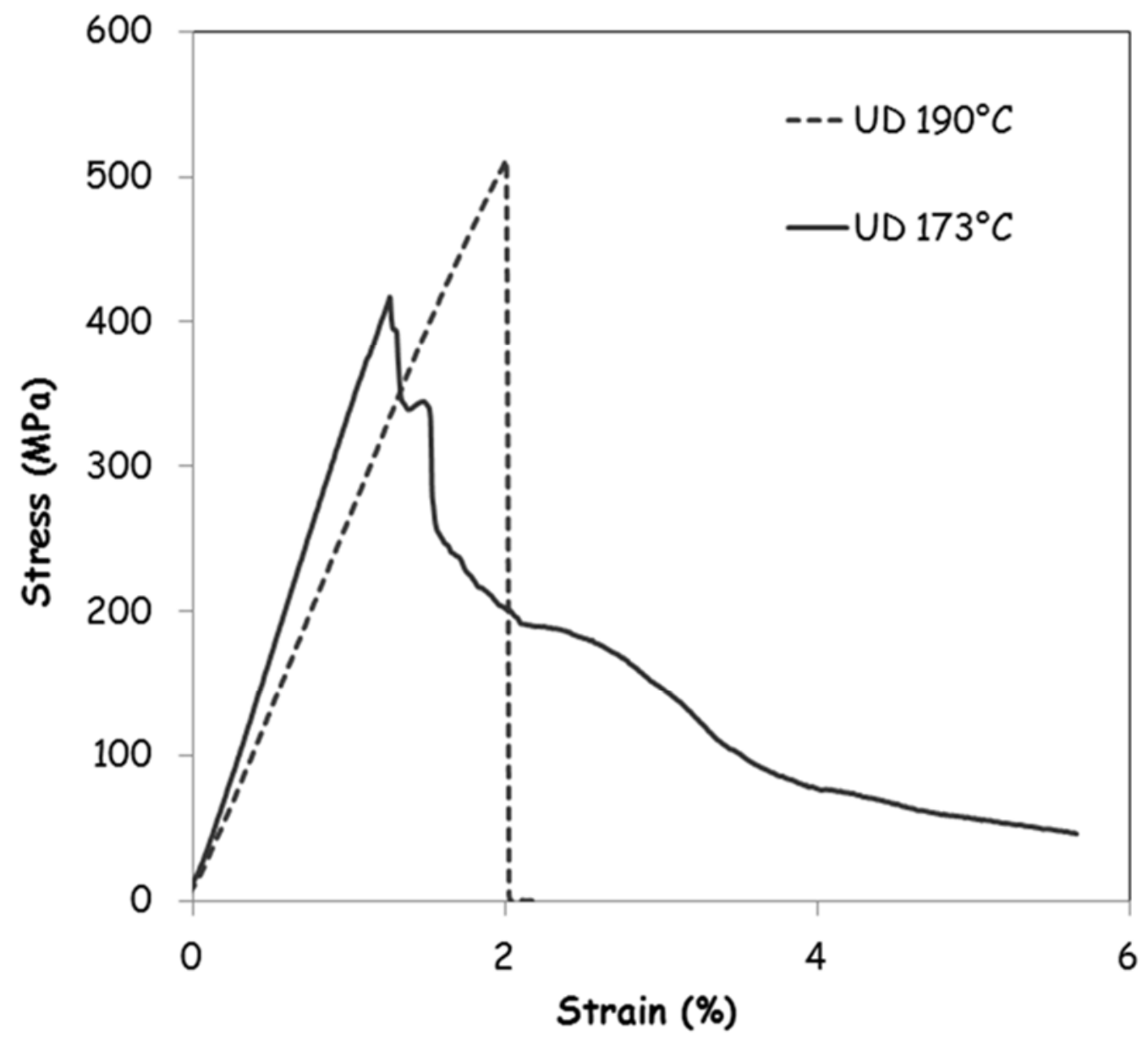

Figure 9: Bending tests (in the fibre direction) for a UD sample compacted in the melting range of the fibre and a UD sample completely melted (made at $\left.190^{\circ} \mathrm{C}\right)$.

Second, and perhaps even more interestingly, if the PA12 filaments were completely melted (by processing at temperature of $190^{\circ} \mathrm{C}$ ), then the sample reverted to brittle failure in bending. This demonstrates the benefit of retaining molecular orientation in the sample, by establishing an optimum temperature in the melting range of the PA12 fibres.

\subsection{Braided samples - $22 \%$ carbon fibre tows}

The next series of tests were carried out using the braided cloth, manufactured over the same temperature range. Figure 10 shows typical tensile results from these samples. It is seen that the samples made at the lower compaction temperatures (176 and below) showed a non-linear behavior as the strain increased, suggesting strongly that the stress transfer between the carbon fibres and PA12 matrix was not satisfactory. A strong candidate for this behavior is that at these lower compaction temperatures, there is insufficient selectively melted material produced by the hot compaction process to fill all the spaces in the braided cloth as the bundles in this configuration will not pack as well as a UD configuration. These results suggest that for this braided cloth, and for the $22 \%$ carbon fibre tows, a homogeneously bonded sample could not be made at the optimum compaction temperature established from the UD tests of $176^{\circ} \mathrm{C}$. At a temperature of $178^{\circ} \mathrm{C}$, the stress-strain curve is seen to be linear with a significantly increased strength. At this temperature sufficient melted and recrystallised matrix phase was produced to give good consolidation for the slightly less well packed structure (braided vs UD fibre arrangement). However, as illustrated by the DSC and WAXS measurements described above for the UD samples, a temperature of $178^{\circ} \mathrm{C}$ is considered too close to the temperature 
where substantial melting, and loss of molecular orientation, occurs $\left(179^{\circ} \mathrm{C}\right)$, suggesting that a commercially realistic processing window is not achievable with braided $22 \%$ carbon fibre co-mingled tows (unless in a tightly packed UD configuration). One possibility would be to add thin interleaved films of the same PA12 polymer, which is a technique we have used in previous non-hybrid SRPC studies (PP [29] and PE [30]) although there will still be a significant challenge in moving the high viscosity PA12 polymer into the braided cloth. This will form the basis of future studies.

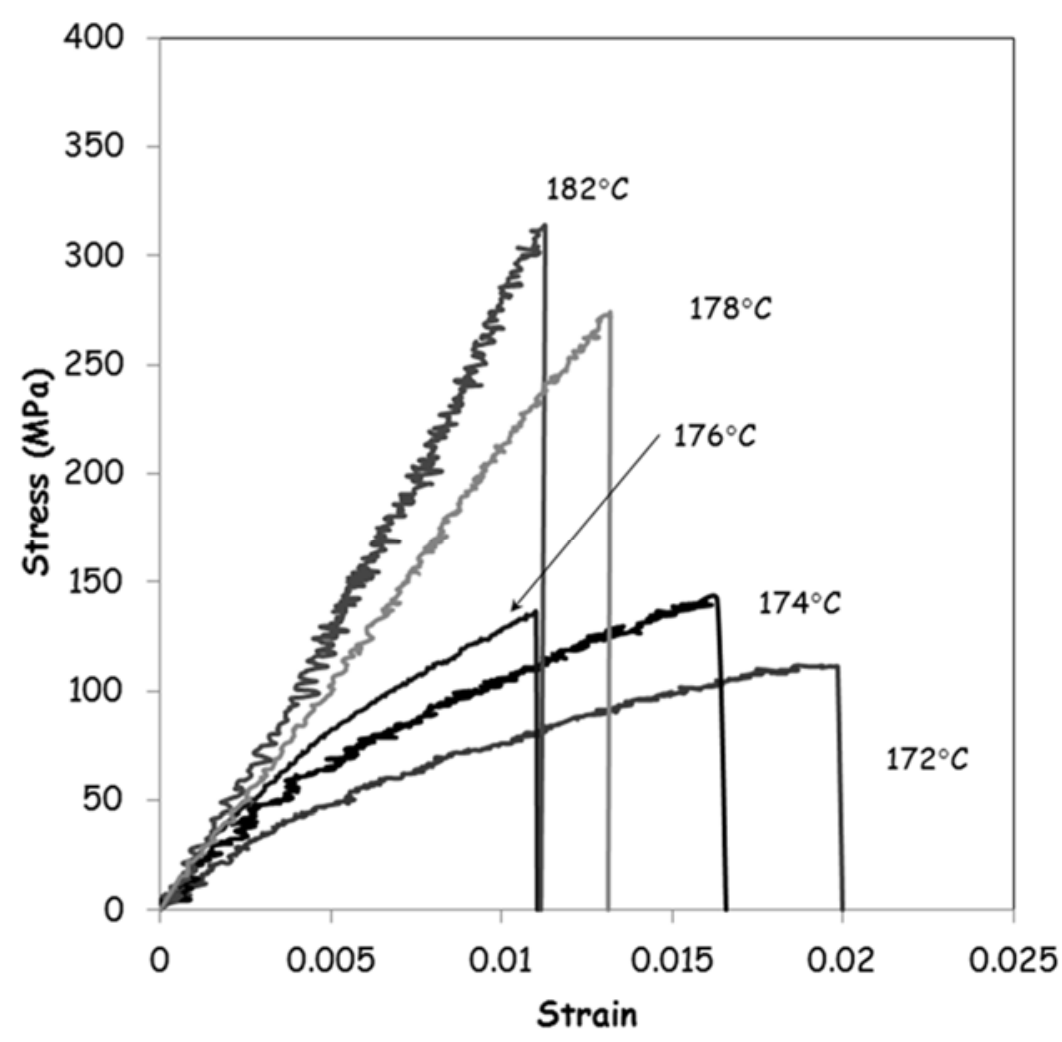

Figure 10: Tensile tests on braided samples made at a range of different hot compaction temperature $-22 \%$ carbon fibre fraction samples

\subsection{UD and Braided samples - $13 \%$ carbon fibre tows}

\subsubsection{UD samples}

The results from the $22 \%$ carbon/PA12 co-mingled fibre tows described in section 3.3 suggest that applying the hot compaction technique produced interesting mechanical properties, but only in a very narrow temperature window and for a UD fibre arrangement. A second set of experiments was carried out using 13\% carbon fibre co-mingled tows, wound into a UD configuration. Figure 11 shows the results from the 13\% volume fraction UD-co-mingled tows in comparison with those shown previously for the $22 \%$ carbon fibre tows (both made at $176^{\circ} \mathrm{C}$ ).

In the fibre direction the properties were once again, almost independent of the compaction temperature. The results shown in Figure 11a compare the tensile stress-strain curves of the $22 \%$ and $13 \%$ fraction tows, at the same compaction temperature of $173^{\circ} \mathrm{C}$. The stiffness and strength, for the $13 \%$ fraction of carbon fibres, were, as expected, approximately a half of that for the $22 \%$ fraction. Average values for the $13 \%$ carbon fibre fraction tows were a tensile modulus of $29.5 \pm 1.7 \mathrm{GPa}$, a tensile strength of $316 \pm 18 \mathrm{MPa}$ and a failure strain of $1.0 \pm 0.1 \%$.

It was found that the transverse strength (Figure 11b), at a comparable compaction temperature, was significantly higher for the lower fraction of carbon fibres. This could be due to two different effects. 
First, the reduction of the carbon fibre fraction, and associated increase in the PA12 fibre fraction will result in a greater proportion of the melted and recrystallised matrix material produced at any compaction temperature. Secondly, the $13 \%$ carbon fibre fraction tows are seen to significantly smaller (Figure 3) and so easier to wet. The combined effect is to widen the effective processing window, as a lower compaction temperature can now be used $\left(175-176^{\circ} \mathrm{C}\right)$, thereby giving a greater distance away from the temperature at which substantial crystalline melting occurs $\left(178^{\circ} \mathrm{C}\right)$.

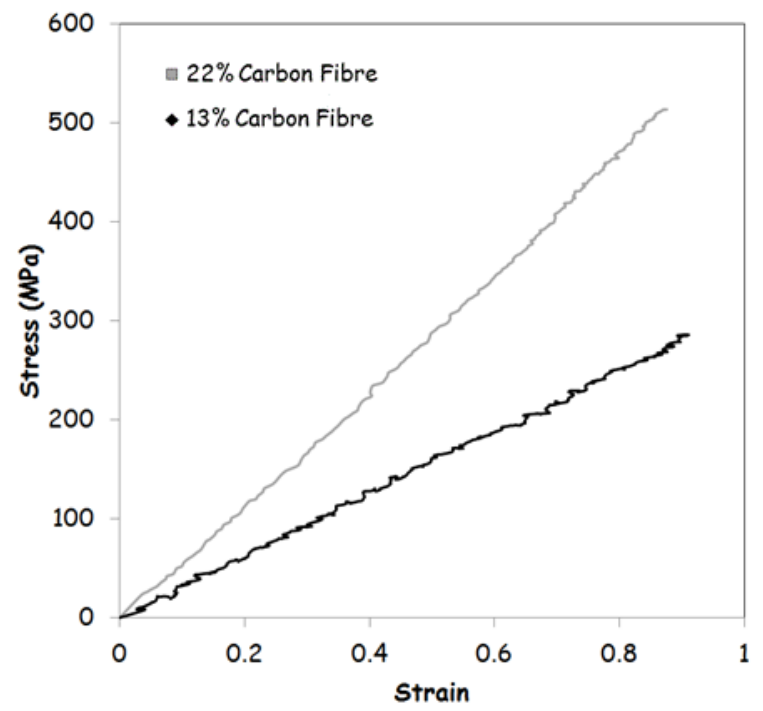

(a)

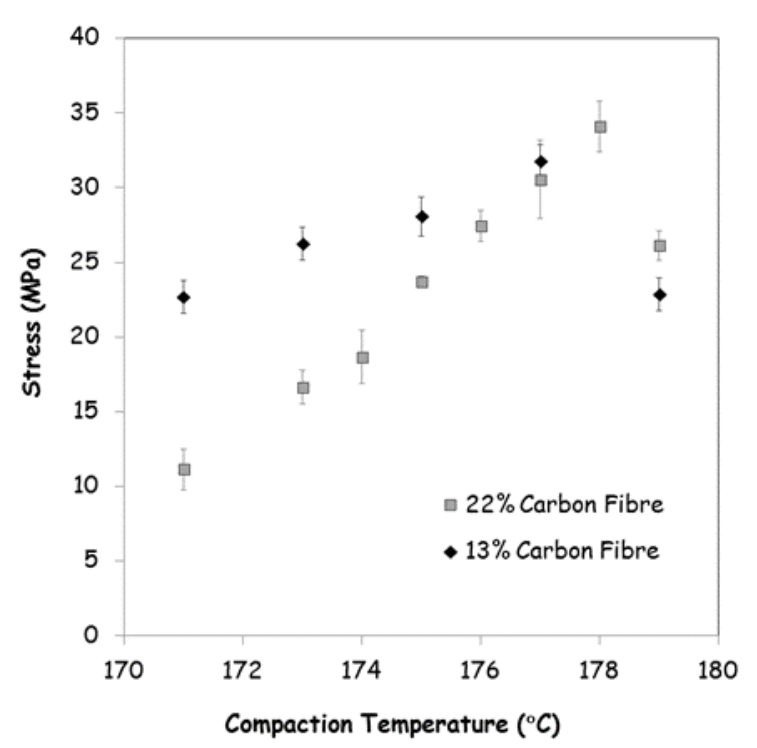

(b)

Figure 11: A comparison of the UD tensile results for samples made with $22 \%$ and $13 \%$ carbon fibre fraction comingled tows. a) typical stress-strain curves from longitudinal tests in the fibre direction made at a compaction temperature of $176^{\circ} \mathrm{C}$ b) transverse tensile strength

\subsubsection{Braided samples}

The $13 \%$ carbon fibre tows were again braided and compacted over a range of temperatures. Samples were compacted first using a temperature of $175^{\circ} \mathrm{C}$, suggested by the UD tests. Figure 12 depicts tensile and bending results for this sample compared to that made previously with the $22 \%$ co-mingled tows, also at $175^{\circ} \mathrm{C}$.

The results shown in Figure 12a indicate that for the braided cloth using the 13\% carbon fibre fraction co-mingled tows, a well bonded sample could be made at a lower temperature $\left(175^{\circ} \mathrm{C}\right)$ than for the $22 \%$ tows tested previously, which required a temperature of $178^{\circ} \mathrm{C}$ to produce a homogeneous sample. Although the sample had an expected lower modulus (with half the amount of carbon fibres), the tensile stress-strain curve was more linear leading to a comparable strength. This could be due to the better impregnation (a greater percentage of matrix material and thinner tows for improved wetting) of the carbon fibre tows, combined with the lower crimp from this smaller diameter tow.

As discussed previously, the importance of this result is that this gives a usable temperature processing window, where a well consolidated sample can be made at $175^{\circ} \mathrm{C}$, while retaining a substantial fraction of the oriented PA12 fibres. 


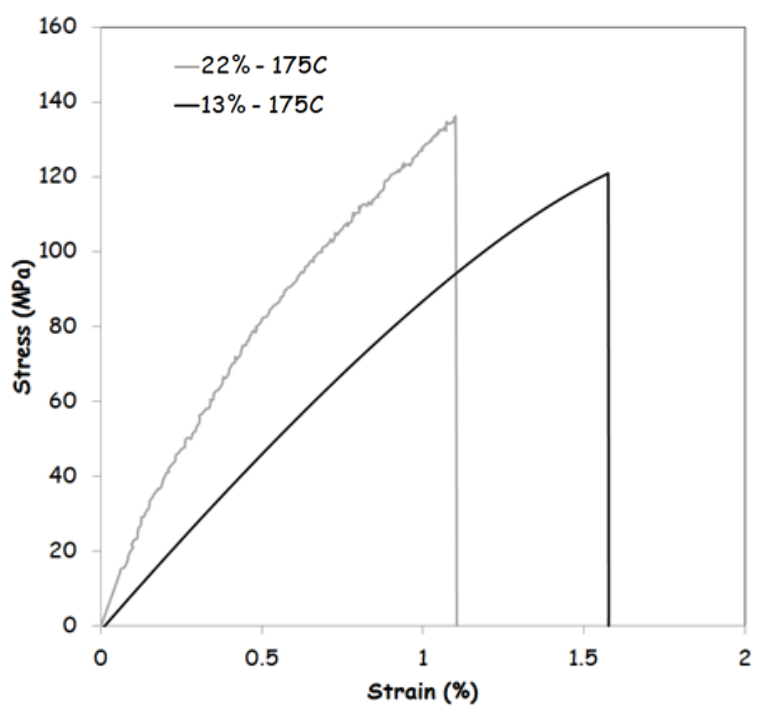

(a)

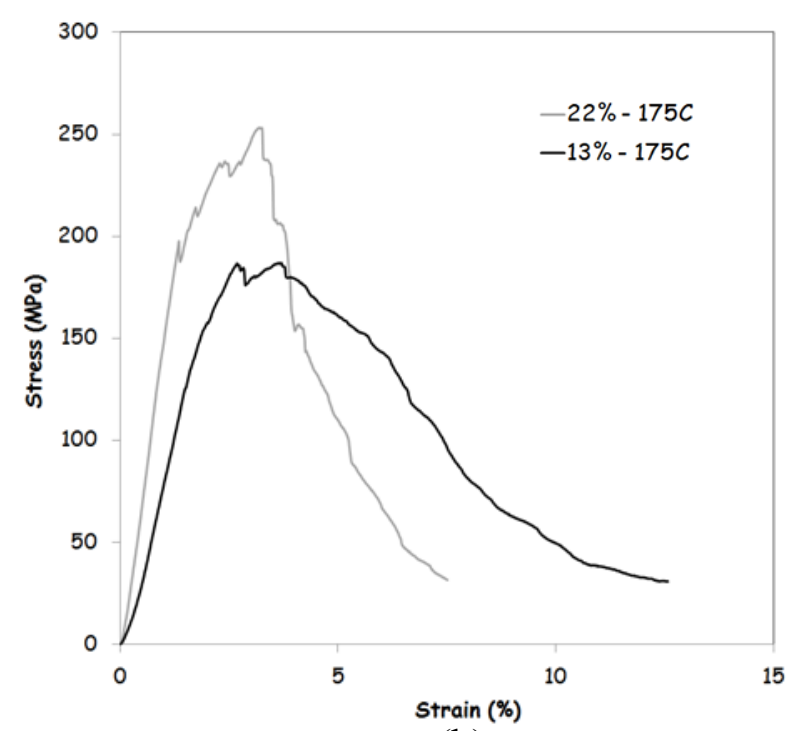

(b)

Figure 12: A comparison of test results for the $22 \%$ and $13 \%$ carbon co-mingled tows and braided cloth. a) tensile test results and b) bending results. All made at $175^{\circ} \mathrm{C}$

Bending tests were next carried out, again comparing the behaviour of the $22 \%$ and $13 \%$ carbon fibre fraction tows. The bending results (Figure 12b) reflect those seen in tension. The $13 \%$ sample showed a lower modulus, as expected, but only a slightly lower strength. However, the ductility of the $13 \%$ sample was improved compared to the $22 \%$ carbon fibre fraction. The results confirm that a carbon fibre fraction of $13 \%$ is a good compromise, delivering increased stiffness and strength over a pure PA12 single polymer composite, while still giving an adequate proportion of the melted fraction from the oriented PA12 fibres to enable consolidation using the hot compaction technique. The following are considered to be the optimum processing conditions for the 13\% co-mingled tows: hot compaction temperature $175 \pm 1{ }^{\circ} \mathrm{C}$, Compaction pressure $5 \mathrm{MPa}$, dwell time at temperature 2minutes and fast water cooling. Table 1 summarises the average mechanical properties of samples made under these conditions (three samples) for both tension and bending loading.

Table 1: Properties of compacted braided cloth

(13\% carbon fibre fraction - optimum processing conditions).

\begin{tabular}{lc}
\hline \multicolumn{2}{c}{ Co-mingled PA12 carbon fibres } \\
0/90 properties - braided cloth \\
\multicolumn{2}{c}{ Carbon fibre fraction $13 \%$} \\
\hline Tensile Modulus (GPa) & $10.1 \pm 0.5$ \\
Tensile Strength (MPa) & $132 \pm 2$ \\
Strain to failure (\%) & $1.5 \pm 0.1$ \\
Bending Modulus (GPa) & $9.5 \pm 0.3$ \\
Bending Strength (MPa) & $185 \pm 4$ \\
Strain to failure (\%) & $>12$ \\
\hline
\end{tabular}

\section{Conclusions}

Experiments have proven that the optimum temperature required for production of hybrid single polymer composites using the hot compaction technique depends on both the arrangement and size of 
the hybrid tows coupled to the carbon fibre fraction. For $22 \%$ volume fraction of carbon fibres, a well consolidated sample could be made at a temperature of $176^{\circ} \mathrm{C}, 2^{\circ} \mathrm{C}$ below the temperature at which major crystalline melting of the oriented PA12 fibres, and loss of molecular orientation, occurs. For braided cloth made from the same co-mingled tows, a higher temperature of $178^{\circ} \mathrm{C}$ was required to give a well consolidated sample, which is too close to the critical temperature.

Reducing the volume fraction of carbon fibres to $13 \%$, with an associated decrease in the tow size, gave a better result. Here, it was found that a well consolidated sample could be made from braided cloth using a lower temperature of $175^{\circ} \mathrm{C}$. At this temperature, sufficient melted and recrystallised matrix material was produced to consolidate the structure and produce a homogeneous composite. This temperature was $3^{\circ} \mathrm{C}$ below the temperature at which substantial crystalline melting occurred, giving a usable temperature processing window.

In tension the samples were found to fail in a brittle manner, with the whole sample breaking on failure of the carbon fibres. Importantly, the hybrid samples were found to show ductile behaviour in bending as long as a substantial proportion of the molecular orientation of the PA12 fibres was retained. If the PA12 were completely melted, then the sample reverted to brittle behaviour.

\section{Acknowledgements}

HIVOCOMP is funded under the topic NMP-2009-2.5-1 "Light high-performance composites" of the 7th Framework Programme for Research and Technological Development). The authors thank the Agency for Innovation by Science and Technology in Flanders (IWT) for the grant of Y. Swolfs. I. Verpoest holds the Toray Chair in Composite Materials at KU Leuven.

\section{References}

[1] Pegoretti A, Fabbri E, Migliaresi C, Pilati F. Intraply and interply hybrid composites based on Eglass and poly(vinyl alcohol) woven fabrics: tensile and impact properties. Polymer International. 2004;53(9):1290-7.

[2] Saw SK, Sarkhel G, Choudhury A. Preparation and characterization of chemically modified JuteCoir hybrid fiber reinforced epoxy novolac composites. J Appl Polym Sci. 2012;125(4):3038-49.

[3] Wan YZ, Lian JJ, Huang Y, He F, Wang YL, Jiang HJ, et al. Preparation and characterization of three-dimensional braided carbon/Kevlar/epoxy hybrid composites. J Mater Sci. 2007;42(4):1343-50.

[4] Czel G, MR W. Demonstration of pseudo-ductility in high performance glass/epoxy composites by hybridisation with thin-ply carbon prepreg. Composites Part A: Applied Science and Manufacturing 2013;52:22-30.

[5] Von Lacroix F, Werwer M, Schulte K. Solution impregnation of polyethylene fibre polyethylene matrix composites. Compos Pt A-Appl Sci Manuf. 1998;29(4):371-6.

[6] Marais C, Feillard P. Manufacturing and Mechanical Characterization of Unidirectional Polyethylene-Fiber Polyethylene-Matrix Composites. Compos Sci Technol. 1992;45(3):247-55.

[7] Teishev A, Incardona S, Migliaresi C, Marom G. Polyethylene fibers-polyethylene matrix composites: Preparation and physical properties. J Appl Polym Sci. 1993;50:503-12.

[8] Hinrichsen G, Kreuzberger S, Pan Q, Rath M. Production and characterization of UHMWPE fibers LDPE composites. Mech Compos Mater. 1996;32(6):497-503.

[9] Lacroix F, Lu HQ, Schulte K. Wet powder impregnation for polyethylene composites: preparation and mechanical properties. Compos Pt A-Appl Sci Manuf. 1999;30(3):369-73.

[10] Pegoretti A, Zanolli A, Migliaresi C. Preparation and tensile mechanical properties of unidirectional liquid crystalline single-polymer composites. Compos Sci Technol. 2006;66(13):1970-9.

[11] Alcock B, Cabrera NO, Barkoula NM, Reynolds CT, Govaert LE, Peijs T. The effect of temperature and strain rate on the mechanical properties of highly oriented polypropylene tapes and all-polypropylene composites. Compos Sci Technol. 2007;67(10):2061-70. 
[12] Alcock B, Cabrera NO, Barkoula NM, Peijs T. Direct Forming of All-Polypropylene Composites Products from Fabrics made of Co-Extruded Tapes. Applied Composite Materials. 2009;16(2):117-34.

[13] Hine PJ, Ward IM, Olley RH, Bassett DC. The Hot Compaction of High Modulus Melt-Spun Polyethylene Fibers. J Mater Sci. 1993;28(2):316-24.

[14] Ward IM, Hine PJ, Norris KE. Polymeric Materials. British Patent Office GB2253420; March 1992.

[15] Ward IM, Hine PJ. The science and technology of hot compaction. Polymer. 2004;45(5):1413-27.

[16] Hine PJ, Ward IM, Jordan ND, Olley RH, Bassett DC. A comparison of the hot-compaction behavior of oriented, high- modulus, polyethylene fibers and tapes. J Macromol Sci-Phys. 2001;B40(5):959-89.

[17] Hine PJ, Ward IM, Jordan ND, Olley RH, Bassett DC. The hot compaction behaviour of woven oriented polypropylene fibres and tapes. I. Mechanical properties. Polymer. 2003;44:1117-31.

[18] Hine PJ, Ward IM. Hot compaction of woven poly(ethylene terephthalate) multifilaments. J Appl Polym Sci. 2004;91(4):2223-33.

[19] Hine PJ, Ward IM. Hot compaction of woven nylon 6,6 multifilaments. J Appl Polym Sci. 2006;101(2):991-7.

[20] Taketa I, Ustarroz J, Gorbatikh L, Lomov SV, Verpoest I. Interply hybrid composites with carbon fiber reinforced polypropylene and self-reinforced polypropylene. Compos Pt A-Appl Sci Manuf. 2010;41(8):927-32.

[21] Fabich B, Taketa I, Gorbatikh L, Lomov SV, Janetzko S, Gries T, et al. Toughness Improvement in Hybrid Composites Made of Carbon Fibre Reinforced Polypropylene and Self-Reinforced Polypropylene. Recent Advances in Textile Composites2010. p. 3-11.

[22] Kretsis G. A review of the tensile, compressive, flexural and shear properties of hybrid fiberreinforced plastics. Composites. 1987;18(1):13-23.

[23] Manders PW, Bader MG. The strength of hybrid glass-carbon fiber composites 1. Failure strain enhancement and failure mode. J Mater Sci. 1981;16(8):2233-45.

[24] Swolfs Y, Crauwels L, Breda EV, Gorbatikh L, Hine P, Ward I, et al. Tensile behaviour of intralayer hybrid composites of carbon fibre and self-reinforced polypropylene. Composites Part A: Applied Science and Manufacturing. (0).

[25] Ji XL, Wu SJ, Yu CW. Analysis of ramie fiber length changes during the stretch-breaking process. Journal of the Textile Institute. 2012;103(1):99-105.

[26] Su CI, Lai PT. Evaluating the Unevenness of Stretch-Broken Tow in Tow-to-Yarn Direct Spinning. Fibers and Polymers. 2010;11(4):648-53.

[27] Hine PJ, Ward IM, El Matty MIA, Olley RH, Bassett DC. The hot compaction of 2-dimensional woven melt spun high modulus polyethylene fibres. J Mater Sci. 2000;35(20):5091-9.

[28] Wang DL, Shao CG, Zhao BJ, Bai LG, Wang X, Yan TZ, et al. Deformation-Induced Phase Transitions of Polyamide 12 at Different Temperatures: An in Situ Wide-Angle X-ray Scattering Study. Macromolecules. 2010;43(5):2406-12.

[29] Hine PJ, Olley RH, Ward IM. The use of interleaved films for optimising the production and properties of hot compacted, self reinforced polymer composites. Compos Sci Technol. 2008;68(6):1413-21.

[30] Hine PJ, Unwin AP, Ward IM. The use of an interleaved film for optimising the properties of hot compacted polyethylene single polymer composites. Polymer. 2011;52(13):2891-8. 